\section{Gender identity and expression in focus: The report of the United Nations Independent Expert on sexual orientation and gender identity, by Victor Madrigal- Borloz.}

Published by the United Nations on 12/07/2018 United Nations official document number: A/73/152

Zhan Chiam, Julia Ehrt ${ }^{\star \star}$

In his recent report, the United Nations Independent Expert on protection against violence and discrimination based on sexual orientation and gender identity, Victor Madrigal-Borloz, examines the "process of abandoning the classification of certain forms of gender as a pathology" "depathologization"- and elaborates on the "full scope of the duty of the State to respect and promote respect of gender recognition as a component of identity" (p. 2). The report also discusses active measures to respect gender identity and concludes with a list of recommendations. While other United

*) Coordinator, Gender Identity and Expression Programme at International Lesbian, Gay, Bisexual, Trans and Intersex Association (ILGA)

$\star \star)$ Director of Programmes at the International Lesbian, Gay, Bisexual, Trans and Intersex Association (ILGA)

Correspondence to: julia@ilga.org
Nations special procedures and agencies have addressed and condemned violence and discrimination on the grounds of gender identity and expression, this report provides a deeper analysis on its root causes. It is the first special procedures report that exclusively addresses human rights with regard to gender identity and expression, and must be considered a mile-stone in the development and enunciation of international human rights law in this regard.

As a baseline, the report asserts that both "pathologization" of some forms of gender as well as the lack of state protection for and recognition of persons of diverse gender identities are rooted in the misconception that "human nature is to be classified with reference to a male/ female binary system on the basis of the sex assigned at birth (para. 6)." Part of that binary gender system is that it expects all persons to adopt roles, feelings, forms of expression and behaviours which are then considered inherently 'masculine' or 'feminine'. Immanent to this system is a "nefarious power asymmetry between the male and the female" (para. 6). Ill treatment and discrimination of and violence against persons of diverse gender identities and expressions, are one consequence of the gender binary, and the report analyzes the impact this has in legal, medical and social settings.

The Independent Expert welcomes the introduction of trans categories in a new chapter in the updated version of the International Classification of Diseases (ICD-11). Given that the pathologization of those forms of gender has had a "deep impact on public policy, legislation and jurisprudence, and has been penetrating all realms of State action in all regions of the world," (para. 14) depathologization becomes a tool to dismantle and abolish 
harmful legal and policy practices on trans and gender diverse people. The mandate holder further criticizes that maintaining a diagnosis on children ("gender incongruence of childhood") might perpetuate "obstacles to the full enjoyment of human rights by trans people, especially when they are applied in a way to restrict legal capacities or choice" (para. 16).

The report also emphasizes States' obligation "to provide access to gender recognition in a manner consistent with the rights to freedom from discrimination, equal protection of the law, privacy, identity and freedom of expression" (para. 21).

Self-determined gender is a fundamental part of a person's free and autonomous choice in relation to roles, feelings, forms of expression and behaviors, and a cornerstone of the person's identity; ${ }^{1}$ and hence has to be respected and protected by States.

The vast majority of trans and genderdiverse persons in the world, however, do not have access to legal gender recognition. ${ }^{2}$ This legal vacuum is likely to "create a climate that tacitly permits, encourages and rewards with impunity the acts of violence and discrimination against them, and leads to a situation of de facto criminalization," Madrigal-Borloz writes (para. 25).

Other states legally recognize the gender identity of trans persons, but impose abusive requirements which include forced, coerced

1 Inter-American Commission on Human Rights, Violence against Lesbian, Gay, Bisexual, Trans and Intersex Persons in the Americas (2015), para. 16.

2 Zhan Chiam, Sandra Duffy and Matilda González Gil, “Trans legal mapping report: recognition before the law," 2nd ed. (Geneva, International Lesbian, Gay, Bisexual, Trans and Intersex Association, 2017); and Asia Pacific Transgender Network and UNDP, "Legal gender recognition." or otherwise involuntary sterilization, ${ }^{3}$ medical procedures related to transitioning, such as surgeries and hormonal therapies, undergoing medical or psychological diagnosis, and forced divorce and ageof-offspring restrictions. These practices amount to ill-treatment or torture ${ }^{4}$ and further violate trans person's human rights.

The risk for trans and gender-diverse persons to face discrimination and violence is exacerbated when their name and gender marker in official records do not match their gender identity or expression. This can even lead to harassment, humiliation, abuse or arrest by police, ${ }^{5}$ exclusion from schools and the labor market, and poses restrictions in access to housing and health care. ${ }^{6}$ Madrigal-Borloz further asserts that States must refrain from gathering and exhibiting data without a legitimate, proportionate and necessary purpose. He sees this concept of legitimacy, proportion and necessity undermined by the "the pervasive exhibition of gender markers in official and non-official documentation" (para. 37).

The report also shows that States not only fail to protect persons of diverse gender identities, but also actively fuel discrimination, ill-treatment and violence

In cases adjudicated by the United Nations $\mathrm{Hu}-$ man Rights Committee, the Committee has ruled that suffering in a sexual and reproductive health context can amount to cruel, inhuman or degrading treatment in violation of article 7 of the International Covenant on Civil and Political Rights (see CCPR/C/116/D/2324/2013, para. 7.6; CCPR/C/101/D/1608/2007, para. 9.2; and CCPR/C/85/D/1153/2003, para. 7).

4 See A/HRC/31/57, para. 49.

5 See A/HRC/29/33/Add.1, para. 86; CCPR/C/ SUR/CO/3, paras. 27 and 28; and OHCHR, press briefing note on Turkey, Israel/Occupied Palestinian Territory and Yemen, 14 July 2015.

$6 \mathrm{~A} / \mathrm{HRC} / 35 / 21$, para. 58 . 
against trans people by not legally recognizing their gender identities, or only doing so under abusive and restrictive requirements.

Consequently, the Independent Expert concludes with a wealth of recommendations that seek to support States in upholding their human rights obligation vis-à-vis persons of diverse gender identities. States are urged to address violence and discrimination based on gender identity through laws, policies and judicial decisions, including the enactment of hate crime legislation that establishes transphobia as an aggravating factor. They are also urged to swiftly adopt the changes made by the WHO in the ICD in regard to trans categories to eradicate the conception of gender diversity as a pathology from all aspects of everyday life, to eliminate abusive requirements as prerequisites for change of name, legal sex or gender, including forced, coerced or otherwise involuntary sterilization, and to adopt legal gender recognition administrative procedures that are simple and based on self-determination.

Madrigal-Borloz has presented a comprehensive analysis of root causes of the violence and discrimination that trans people face globally in the context of pathologization and state recognition and protection, or rather the lack thereof. Such an investigation is unprecedented in the context of UN special procedures, and demonstrates the Independent Expert's commitment to elevate issues pertaining to gender identity. The report's timely and useful analysis has long been overdue in the context of the international human rights framework.

\section{Fallgirls: Gender and the Framing of Torture at Abu Ghraib (Classical and Contemporary Social Theory), by Ryan Ashley Caldwell.}

Published by Routledge Books. 2017. New York. (ISBN 978-1-4094-2969-2)

\section{Pau Pérez-Sales ${ }^{\star}$}

Initially published in 2012 and now reedited, this book constitutes a peculiar contribution to the torture literature on perpetrators. Existing books have already covered: self-justifying perspectives written by perpetrators (i.e. Aussaresses, 2010; Moore-King, 1998; Pardo, 2014; Troccoli, 1996); interviews with perpetrators or analysis from autobiographical texts (i.e. Conroy, 2000; Crelinsten \& Schmid, Alex P (Eds.), 1995; Haritos-Fatouros, 2003; Payne, 2008; Pérez-Sales, 2017); and analysis of the interaction from a survivor's viewpoint (Gil, 1999). There also exists a wealth of social psychology books that attempt to theorize the logic and dynamics of becoming a perpetrator (i.e. Bandura, Barbaranelli, Caprara, \& Pastorelli, 1996; Browning, 1992; Miller, 2004; Staub, 1999). Caldwell's book adopts the extreme hypothesis that the soldiers England and Harman, judged for acts of misconduct in Abu Ghraib after the leakage of dozens of terrible pictures,

*) Editor-in-Chief, Torture Journal

Correspondence to: pauperez@arrakis.es 